\title{
Novel Battery Charging Control System for Batteries Using On/Off and Pwm Controllers for Stand Alone Power Systems
}

\author{
Mohammed Shoaib ${ }^{1}$, V Nagaraj ${ }^{2}$ \\ ${ }^{1} P G$ student Department of Electrical \&Electronics engineering, \\ ${ }^{2}$ Assoc.Prof. (Senior Scale), Manipal Institute of Technology, Manipal University, Manipal, India
}

\begin{abstract}
Photovoltaic or in short term PV is one of the renewable energy resources that recently has become broader in nowadays technology. The demand or future work is looking for high efficiency, more reliable and economical price PV charge controller which is come in portable size has become very popular in PV system. In this paper, two different topologies of chargers will be simulated using proteus professional software. Both configurations are designed based on microcontroller (Atmega 32) which reduces complexity in the number of electronic components and increased monitoring and regulative functions. Pulse width modulation (PWM) will be implemented on a MCU to control duty cycle and voltage. Liquid Crystal Display (LCD) is used to display the voltage from rechargeable battery. The benefit of this project is an improvement of efficiency depend on duty cycle and voltage change.
\end{abstract}

Keywords - PV, MCU, PROTEUS, VRR,

\section{Introduction}

A charge controller is needed in photovoltaic system to safely charge sealed lead acid battery [1]. The most basic function of a charge controller is to prevent battery overcharging. If battery is allowed to routinely overcharge, their life expectancy will be dramatically reduced. A charge controller will sense the battery voltage, and reduce or stop the charging current when the voltage gets high enough. This is especially important with sealed lead acid battery where we cannot replace the water that is lost during overcharging. Unlike Wind or Hydro System charge controller, PV charge controller can open the circuit when the battery is full without any harm to the modules [3], [5]. Most PV charge controller simply opens or restricts the circuit between the battery and PV array when the voltage rises to a set point. Then, as the battery absorbs the excess electrons and voltage begins dropping, the controller will turn back on. Some charge controllers have these voltage points factorypreset and non adjustable, other controllers can be adjustable [1].

Important functions of battery charge controllers and system controls are to [2]:

- Prevent Battery Overcharge: to limit the energy supplied to the battery by the PV array when the battery becomes fully charged.

- Prevent Battery Over discharge: to disconnect the battery from electrical loads when the battery reaches low state of charge.

- Provide Load Control Functions: to automatically connect and disconnect an electrical load at a specified time, for example operating a lighting load from sunset to sunrise.

- A series charge controller or series regulator disables further current flow into batteries when they are full. A shunt charge controller or shunt regulator diverts excess electricity to an auxiliary or "shunt" load, such as an electric water heater, when batteries are full.

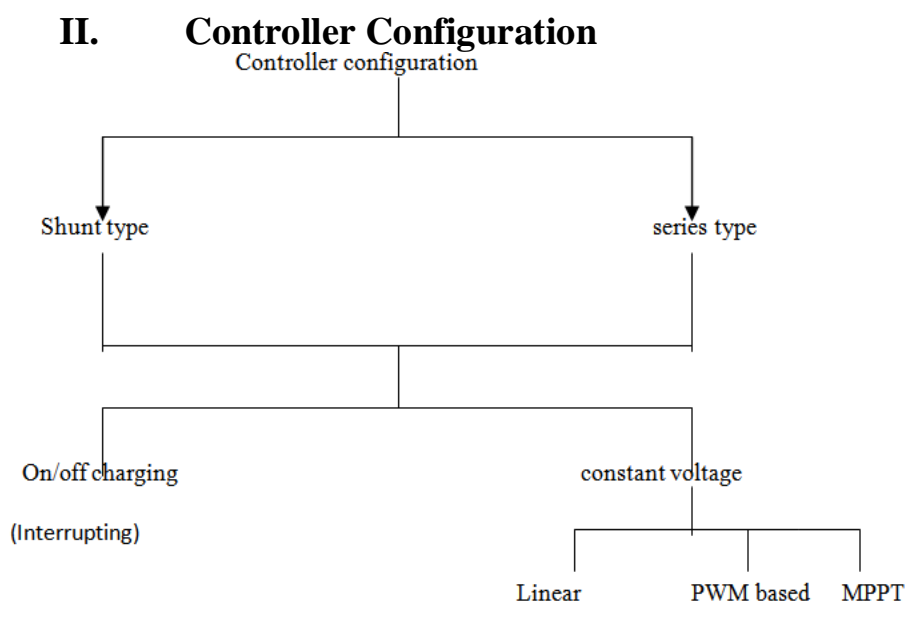


In shunt type controllers shown in fig1, diverts array energy to a parallel (or shunt) path when the batter reaches the full charge VR set point. Charging is then resumed once battery voltages fall below the VRR set point. This approach is not recommended for larger systems, since power losses in the switching element are high and require a means of heat dissipation.

In series type controllers, shown in fig 2, terminates charging at the VR set point with an in-series element which open circuits the PV array. As with the shunt interrupting on/off controllers charging is then resumed, once battery voltage falls below the VRR set point. These controllers may or may not, require a blocking diode depending on the switching element.

In shunt linear method uses a control element to maintain the battery at the voltage regulation set point as it approaches full charge. By shunting power away from the battery in a linear manner, this provides a constant voltage charge to the battery.

In this controller, a zener diode with reverse voltage rating equal to the VR set point is installed in parallel with the battery. When the battery voltage equals the diode voltage, the diode conducts, shunting as much current necessary to keep the system on a constant voltage charge. In series linear method applies a constant voltage to the battery as it approaches the full charge VR set point by using a series control element which acts like a variable resistor. This element dissipated the balance of the power that is not used to charge the battery.

In pwm based charger ,uses a solid state switches to apply pulses of current at a reasonably high frequency (eg. $300 \mathrm{hz}$ ), but with a varying duty cycle, such that battery receives a constant voltage charge from the array. This type of controller, shown in the fig 3, can also be configured in the shunt topology. Although similar to the series linear and shunt linear controller in function, power dissipation is reduced with PWM topology compared to series linear control.
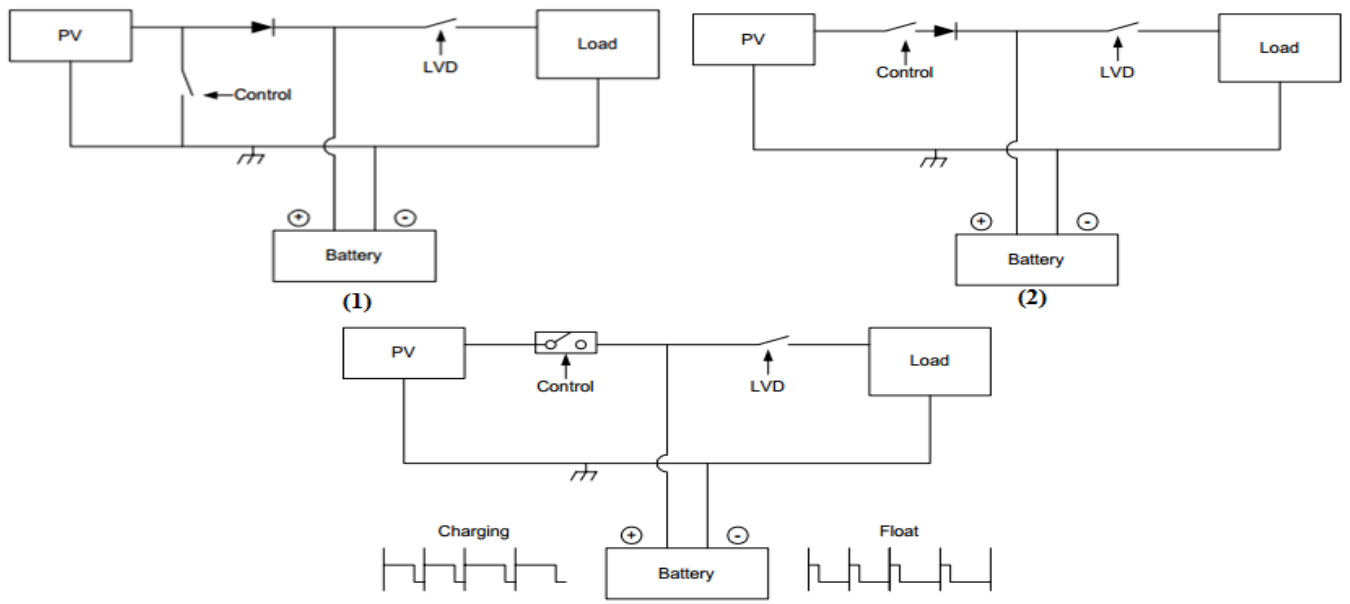

(3)

FIGURE 1, 2, 3- (Block diagram of shunt interrupting (on/off), series interrupting (on/off), series PWM)

III. Schematic Diagram Of Standalone Pv Systems

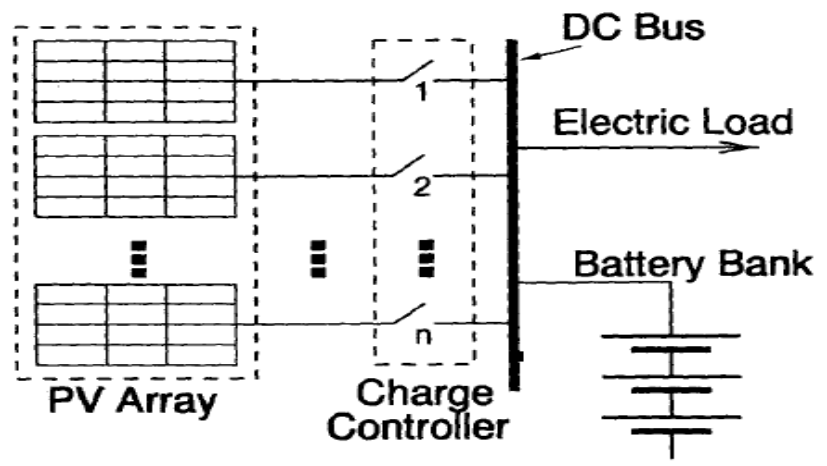

FIGURE 4-(Standalone Pv Systems) 


\section{System Software Design}

ISIS provides the development environment for PROTEUS VSM, our revolutionary interactive system level simulator. This product combines mixed mode circuit simulation, microprocessor models and interactive component models to allow the simulation of complete micro-controller based designs. ISIS provides the means to enter the design in the first place, the architecture for real time interactive simulation and a system for managing the source and object code associated with each project. In addition, a number of graph objects can be placed on the schematic to enable conventional time, frequency and swept variable simulation to be performed. Major features of PROTEUS VSM include:

1. True Mixed Mode simulation based on Berkeley SPICE3F5 with extensions for digital simulation and true mixed mode operation.

2. Support for both interactive and graph based simulation.

3. CPU Models available for popular microcontrollers such as the PIC and 8051 series.

4. Interactive peripheral models include LED and LCD displays, a universal matrix keypad, an RS232 terminal and a whole library of switches, pots, lamps, LEDs etc.

5. Virtual Instruments include voltmeters, ammeters, a dual beam oscilloscope and a 24 channel logic analyzer.

6.

\section{Simulation Of Battery Charger}

4.1 Topology 1(on /off controller)

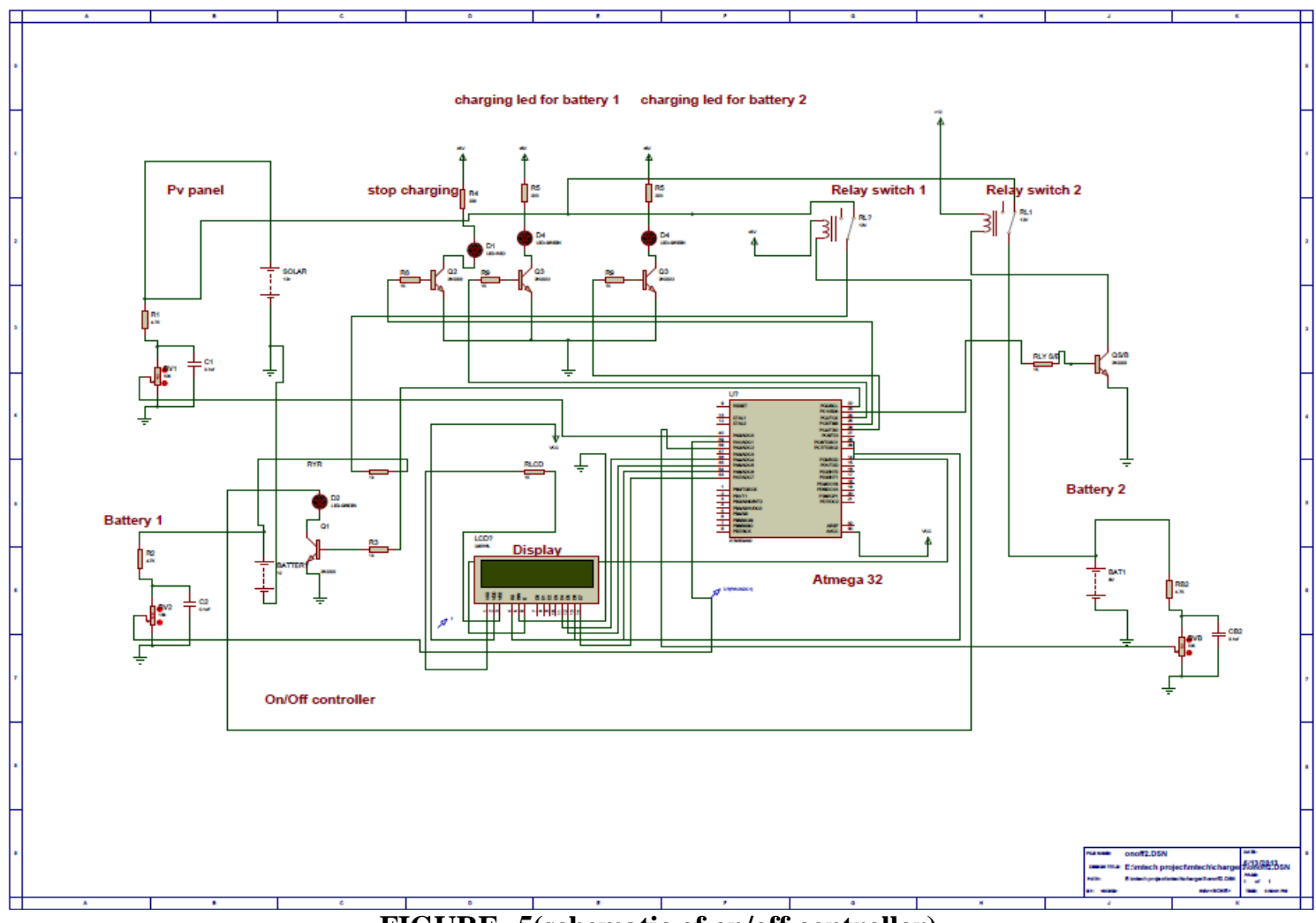

FIGURE -5(schematic of on/off controller)

\subsubsection{Voltage source greater than threshold value.}

A supply source, Vgen (solar voltage) greater than threshold value $(>12 \mathrm{~V})$ is supplied via generator

This can be achieved by increasing the variable resistor value at RV1. If source is greater than threshold value, the controller (ATMEGA ) will measured potential from Vb1 (Voltage battery 1) and Vb2 (Voltage battery 2). When both batteries are high (greater than $11.5 \mathrm{~V}$ ), and both the relays are off as shown in fig 6then high Led is turned on stating both batteries are full (led 1). 


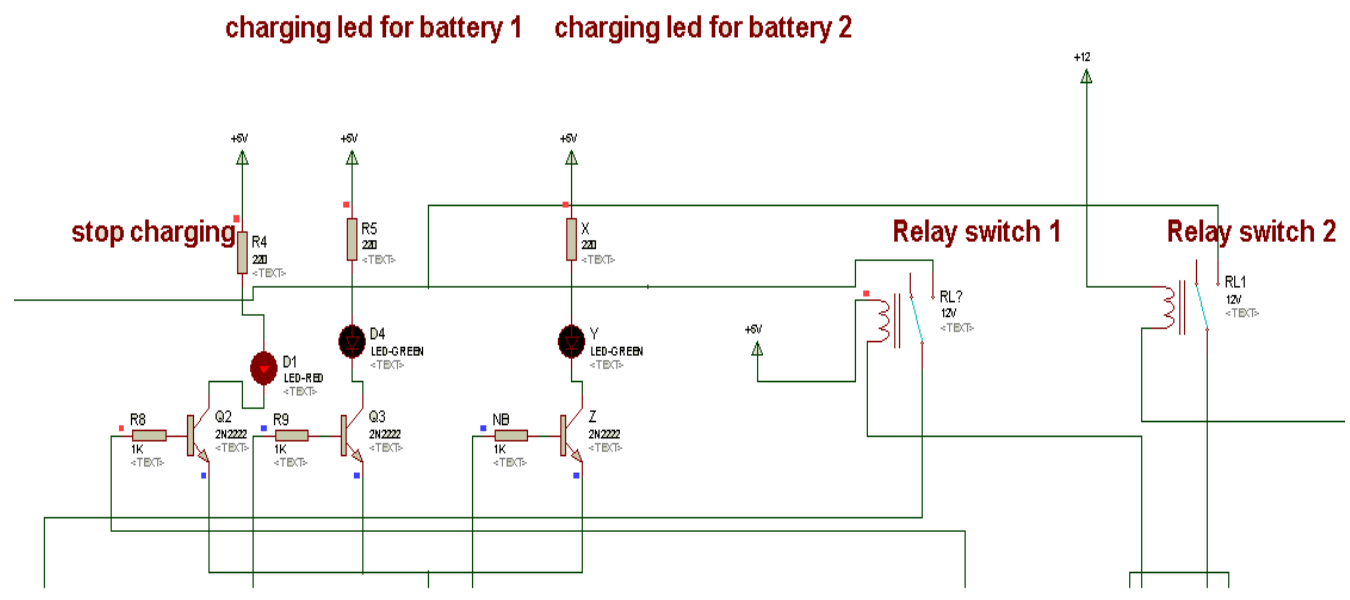

FIGURE-6 (Animation result both relays remains open)

\subsubsection{Charging of battery $1(\mathrm{Va})$.}

$\mathrm{Vb} 1$ is set to low by lowering the variable resistor at RV3. The controller will starts charging by Vb1 charging led is turned on (led2) and high led (led 1) is turned off, as shown in fig 7 relay switch 2 remains open . When $\mathrm{Vb} 1$ is fully charge, the controller will proceed to charge $\mathrm{Vb} 2$, since $\mathrm{Vb} 2$ already fully charge then again high led is turned on.

\section{charging led for battery 1 charging led for battery 2}

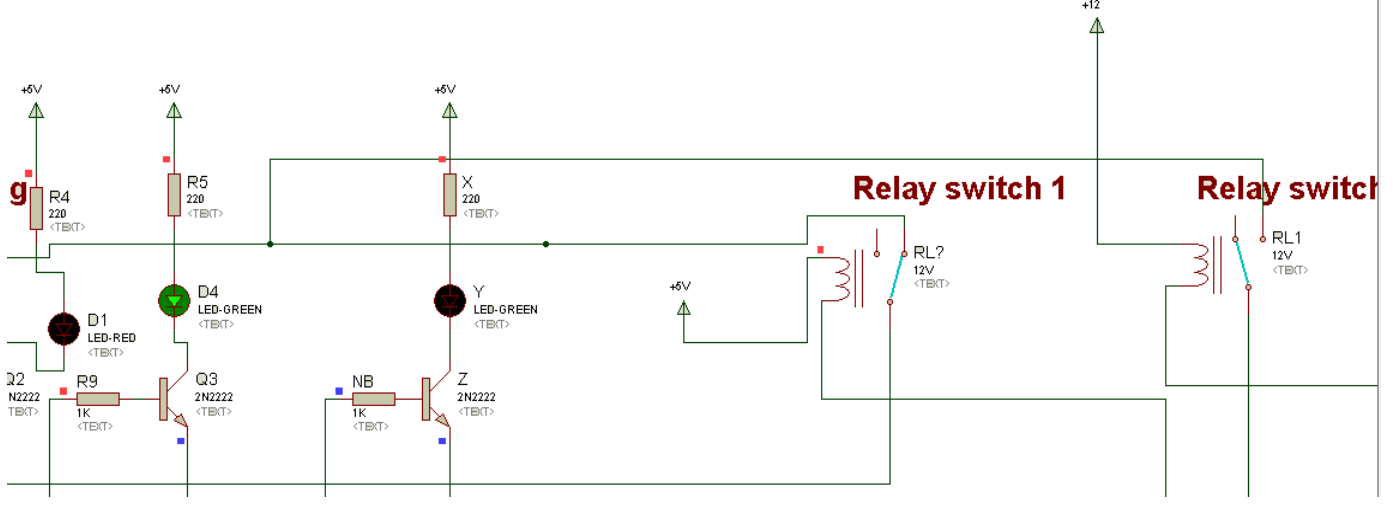

FIGURE-7(animation result of switching the relay)

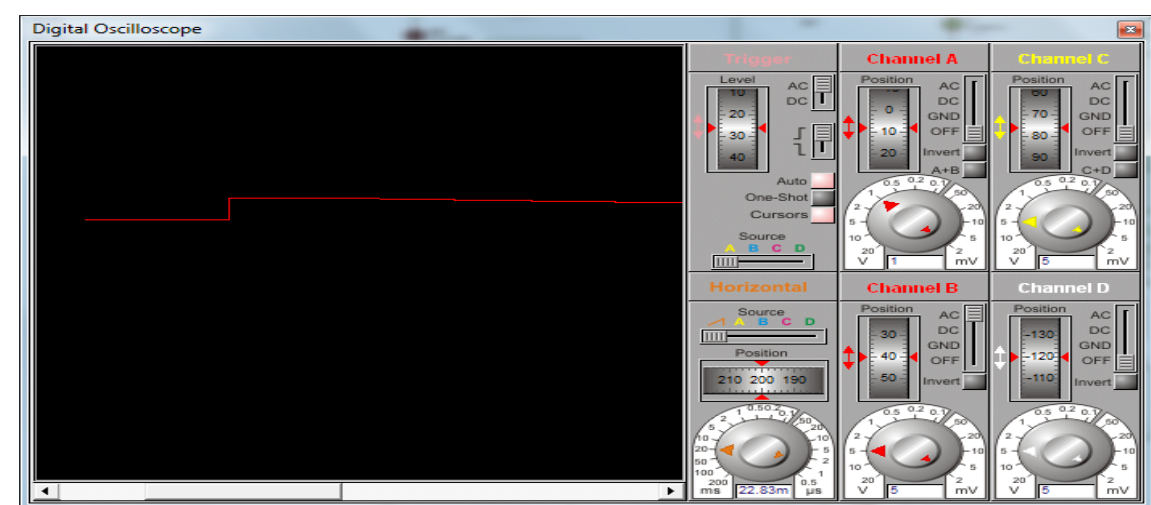

FIGURE-8(channel b of digital oscilloscope shows switching action of relay) 


\subsubsection{Charging of battery $2(\mathrm{Vb})$}

$\mathrm{Vb} 1$ is set to high by increasing the variable resistor at RV3 and lowering Vb2. The controller will starts charging $\mathrm{Vb} 2$ and charging led is turned on for $\mathrm{vb} 2$ (led 3)\& When $\mathrm{Vb} 2$ is fully charge, the controller will proceed to charge $\mathrm{Vb} 1$, since $\mathrm{Vb} 1$ already fully charge then (led 1) is to 'on' again.

\subsubsection{Lower source.}

The source, Vsolar is set again to be less than $12 \mathrm{~V}$, by decreasing RV1. The controller will keep on sampling until Vsolar starts to increase and greater than threshold value

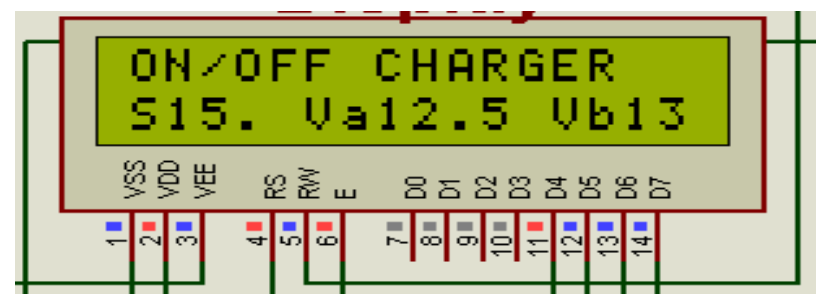

FIGURE 9- (Animation result of display showing solar(s), battery $1(\mathrm{Va}) \&$ battery $2(\mathrm{Vb})$ voltage)

\subsection{Advantages of on/off Battery charger}

- Lower power drop across controller than series configuration

- Often simple, cheap and reliable

- Tapered current charging.

\subsection{Disadvantages of on/off battery charger}

- Significant PD in switching element.

- Blocking diode required

- Can cause hot spots in high voltage arrays

- May have difficulty fully charging batteries At higher currents

- Damages batteries, aging ,heating and gasing

\subsection{Topology 2(PWM charge controller)}

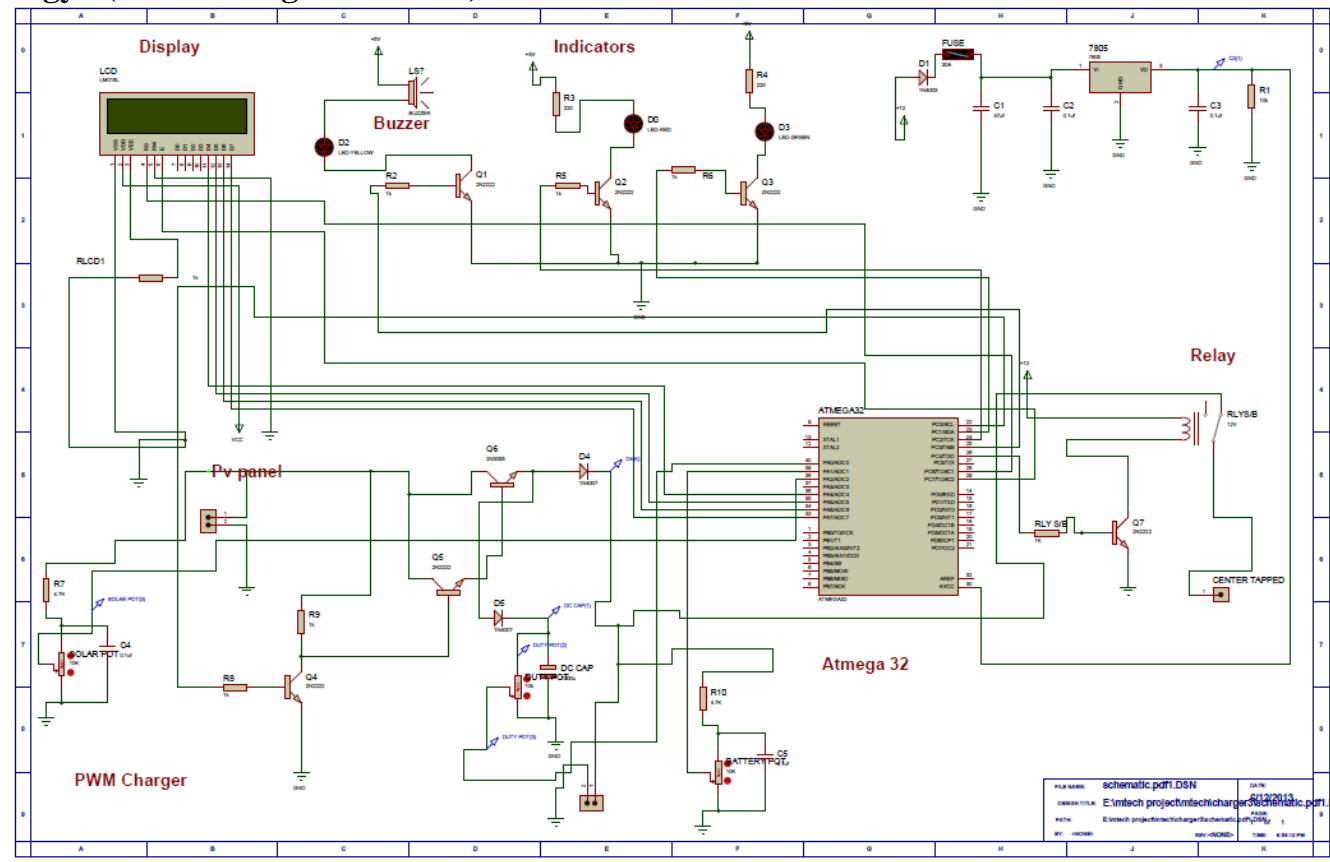

FIGURE -10 (Schematic of pwm charge controller) 


\subsubsection{Operation of System}

Pulse Width Modulation (PWM) is the most effective means to achieve constant voltage battery charging by switching the solar system controller's power devices. When in PWM regulation, the current from the solar array tapers according to the battery's condition and recharging needs. In the fig 8 solar charge is controlled by controlling the duty cycle ,such that an optimum 13.75 volts is fed to battery for charging purpose.2N3055 NPN power transistor, Packaged in a TO-3 case style, it is a $15 \mathrm{amp}, 60$ volt is used as switching device Initially $50 \%$ duty cycle is fed in MCU using PORT C0. As the solar voltage is unregulated the voltage is controlled by adjusting the duty cycle .Two reference voltage is fed in MCU, whenever solar voltage is < reference voltage $V_{1}(>>$ Pwm), similarly vice versa.

\subsubsection{Simulation results of pwm charger}

The proposed charge controller is simulated by using Proreus ISIS 7 Professional for six cases listed in table 1 and the simulation results shown in figures 10-17.

\begin{tabular}{|l|l|l|l|l|l|}
\hline $\begin{array}{l}\text { Test } \\
\text { no }\end{array}$ & $\begin{array}{l}\text { Solar } \\
\text { voltage } \\
\text { (Input) }\end{array}$ & $\begin{array}{l}\text { Battery } \\
\text { voltage }\end{array}$ & $\begin{array}{l}\text { Bucked } \\
\text { voltage } \\
\text { (Output)V }\end{array}$ & $\begin{array}{l}\text { Duty } \\
\text { cycle\% }\end{array}$ & $\begin{array}{l}\text { LED } \\
\text { status }\end{array}$ \\
\hline $\mathbf{1}$ & 19 & 12.0 & 12.75 & $98.6 \%$ & Green \\
\hline $\mathbf{2}$ & 16 & 12.0 & 13.50 & $96.4 \%$ & Green \\
\hline $\mathbf{3}$ & 14 & 12.0 & 13.75 & $46 \%$ & Green \\
\hline $\mathbf{4}$ & 18 & 11.0 & 12.75 & $97.2 \%$ & Yellow \\
\hline $\mathbf{5}$ & 17 & 13.5 & 0 & $0 \%$ & No led \\
\hline $\mathbf{6}$ & 16 & 10.5 & 0 & $0 \%$ & Red \\
\hline
\end{tabular}

TABLE -1

\subsubsection{Algorithm of pwm based charge controller}

As microcontroller software works as sequential basis, it will perform these steps sequentially.

1. Power On, RESET

2. Define Input / Output of the ports

3. Setup ADC for measurement

4. Start ADC Module

5. Measure ADC2, ADC3, ADC4, ADC5. ADC2 for 'Solar Voltage', ADC3 for 'Battery High Set', ADC4 for 'Battery Low Set' and ADC5 for 'Battery Voltage'

6. If 'Battery Voltage' < 'Battery High Set' and 'Solar Voltage' > 'Battery Voltage' then
a. Switch ON Battery Charging
b. Switch ON Charging LED
c. Switch OFF Battery High LED

7. If 'Battery Voltage' $>$ or $=$ 'Battery High Set' then
a. Switch OFF Battery Charging
b. Switch OFF Charging LED
c. Switch ON Battery High LED

8. If 'Solar Voltage' < 'Battery Voltage' then

a. Switch OFF Battery Charging

b. Switch OFF Charging LED

9. If 'Battery Voltage' < or = 'Battery Low Set' then

a. Switch ON Battery Low LED

10. If 'Battery Voltage' > 'Battery Low Set' then

a. Switch OFF battery Low LED

11. Go to Step 5.

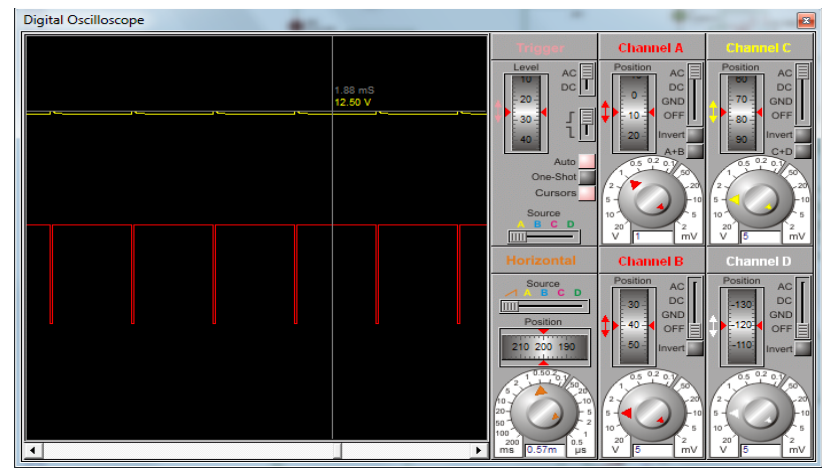


FIGURE 10- (channel A represents the output of the MCU PWM signal,\& channel c is o/p voltage)

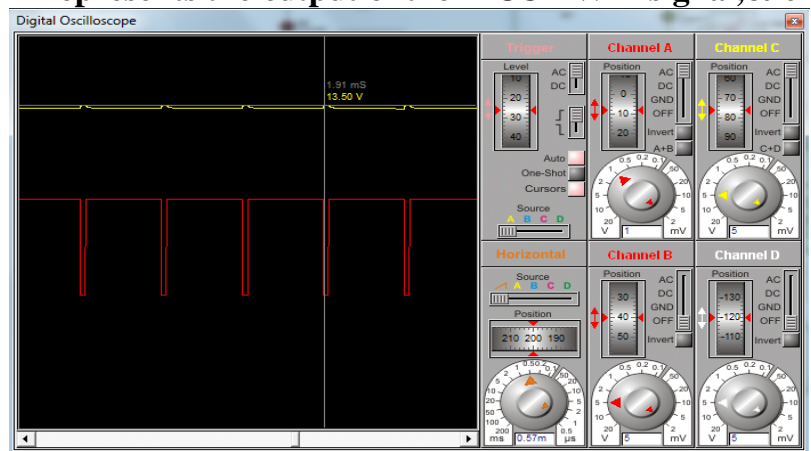

FIGURE 11- (channel A represents the output of the MCU PWM signal,\& channel $\mathrm{c}$ is o/p voltage)

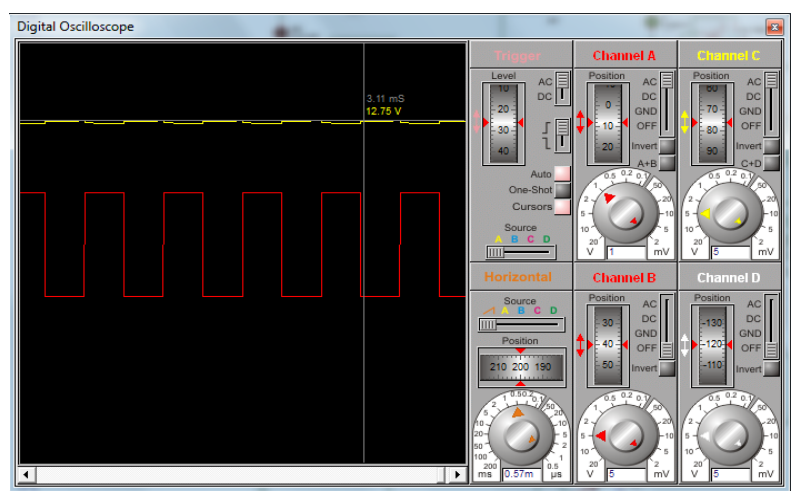

FIGURE 12- (channel A represents the output of the MCU PWM signal,\& channel C is o/p voltage)

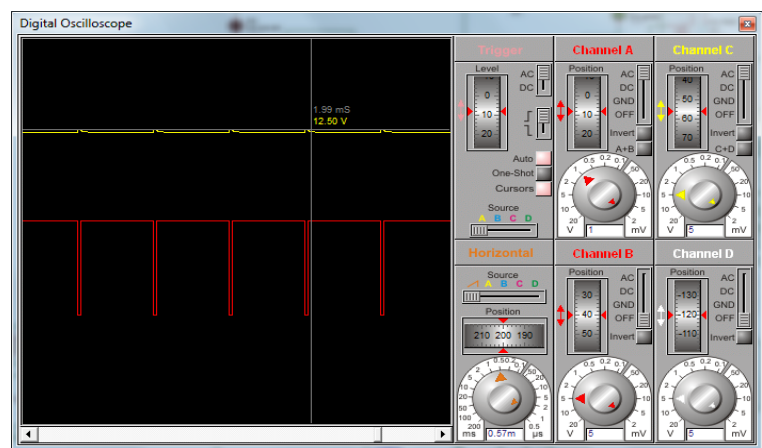

FIGURE 13- (channel A represents the output of the MCU PWM signal,\& channel C is o/p voltage)

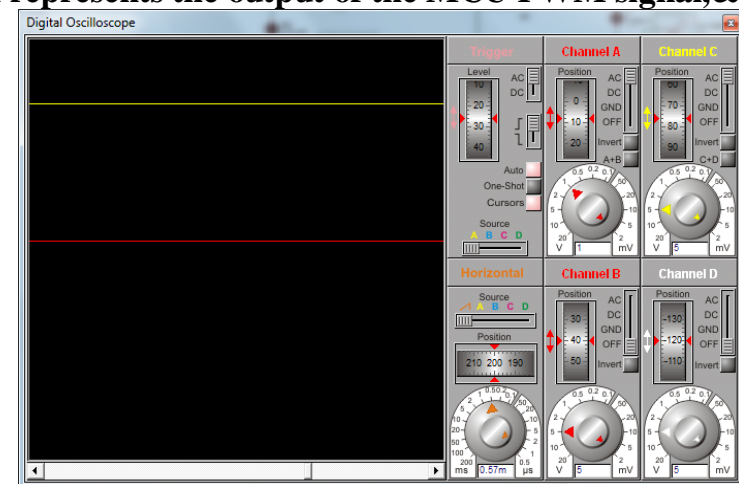

FIGURE 14- (channel A represents the output of the MCU PWM signal,\& channel C is o/p voltage for both test no $5 \& 6$ from table no 1) 


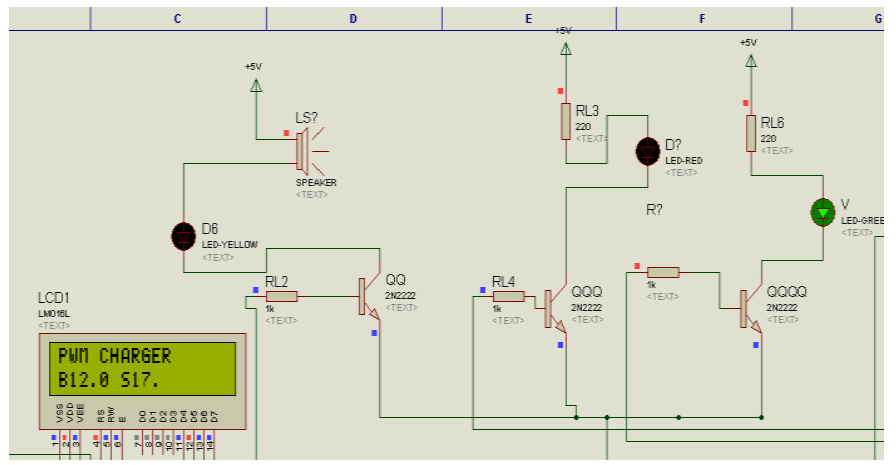

FIGURE 15-(the above schematic refers to step no 6 of the algorithm)

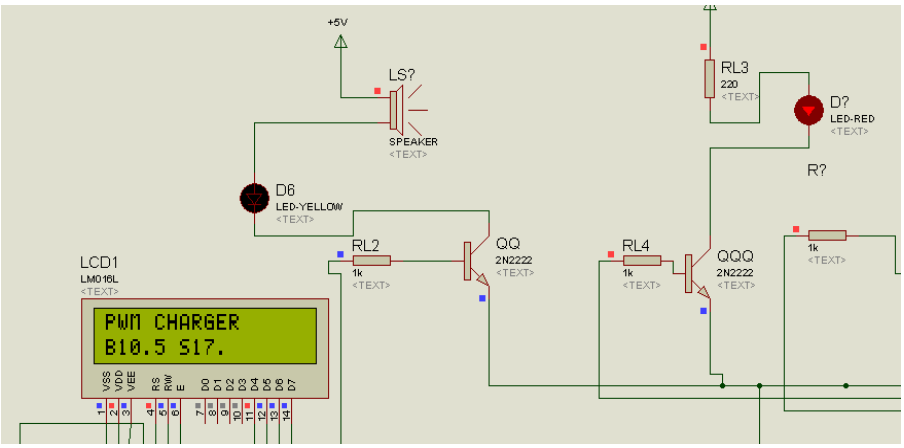

FIGURE 16-(the above schematic refers to test no 6 from table no 1)

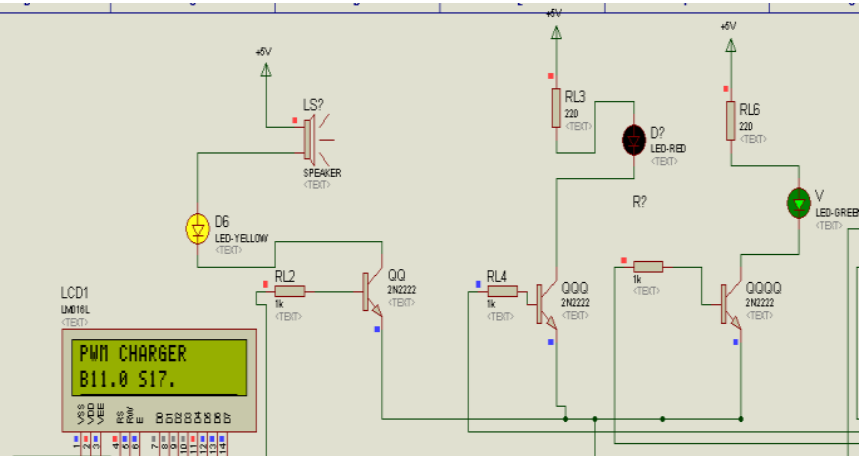

FIGURE 17-(the above schematic refers to test no 4 from table no 1)

\section{Conclusion}

The article is being simulated in the Proteus software, the hardware must be tested accordingly, Proteus not only make many MCU visualize, but also can visualize many MCU examples. This is $80-90 \%$ similar to real operating device The history for on-off regulators has been early battery failures, increasing load disconnects, and growing user dissatisfaction. PWM has recently surfaced as the first significant advance in solar battery charging. PWM solar chargers use technology similar to other modern high quality battery chargers. When a battery voltage reaches the regulation set point, the PWM algorithm slowly reduces the charging current to avoid heating and gassing of the battery, yet the charging continues to return the maximum amount of energy to the battery in the shortest time. The result is a higher charging efficiency, rapid recharging, and a healthy battery at full capacity. In addition, this method of solar battery charging promises some very interesting and unique benefits from the PWM pulsing. These include:

1. Ability to recover lost battery capacity and desulfate a battery.

2. Dramatically increase the charge acceptance of the battery.

3. Maintain high average battery capacities (90\% to $95 \%$ ) compared to on-off regulated state-of charge levels that are typically $55 \%$ to $60 \%$.

4. Equalize drifting battery cells.

5. Reduce battery heating and gassing.

6. Automatically adjust for battery aging \& Self-regulate for voltage drops and temperature effects in solar systems. 


\section{References}

[1] Mohammed shoaib,Prof v nagaraj,,proteus based simulation of PV inverter for rural electrical service (IJMER). Vol 3, Issue 2, MarchApril 2013, pp-1212-1219,

[2] Ahmad Shukri Bin Fazil Rahman, Abdul Rahim Bin Abdul Razak, Proteus Based Simulation of a Charge Controller, 2010 IEEE international conference on power and energy (PEcon2010), kuala lumpur,Malaysia.

[3] Ross, J., Markvart, T., and He, W.: „Modelling Battery charger Regulation for a Stand-alone Photovoltaic System“, Sol. Energy, 2000, 69, pp. 181-190

[4] Singh, P.; Rajagopalan, J.; LaFollette, R.; Fennie, C., Jr.; Reisner, D.E.; "Fuzzy logic-based solar charge controller for microbatteries," Conference Record of the Twenty-Eighth IEEE Photovoltaic Specialists Conference, pp. 1726 - 1729, Sept. 2000.

[5] M. Sharon et al, "Solar rechargeable battery,", electrochimica Acta, Vol. 36, No.7, D.J. Caldwell et al, Solar array voltage regulation study," Proc. of the 27th K.K Govil, "Maximum power points of solar cells with simultaneous series and shunt losses," Int. $i$. Electronics, Vo1.56, 1984,

\section{Acknowledgement}

Authors would like to thank first and foremost to the director of MIT Dr. V.V.Thomas, HOD of Electrical and Electronics Department Dr. B.K Singh. Authors pay their sincere gratitude to the entire faculty of MIT EEE department and especially Prof H.V.Gururaj Rao for the help render during preparation of manuscript.

\section{About The Authors}

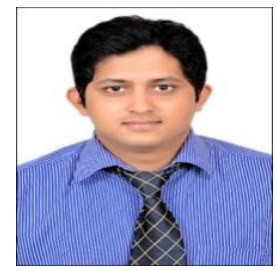

Mohammed Shoaib has obtained his B.E degree in EEE from New horizon college of engineering and currently pursuing his MTECH in power electronics system and control in Manipal University. He has published 1 research paper at International level .His area of interest is Renewable energy resources, power converters and embedded systems.

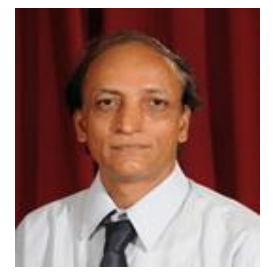

V.NAGARAJ has has obtained his ME in power systems from Mysore university, and $\mathrm{He}$ has 34years of teaching experience. He has published 2 research papers and 1 research paper at national \& International level. His area of teaching is Applications of soft computing systems to power Systems 